\title{
La Nación vs. Alfonsín
}

\section{Preocupaciones empresariales y libertad de expresión (1983-1987)}

\section{La Nación vs. Alfonsín \\ Business Concerns and Freedom of Expression (1983-1987)}

\section{César Luis Díaz}

tatodiaz60@gmail.com

http://orcid.org/0000-0003-0816-642X

\section{Mario Jorge Giménez}

mariojgimenez@yahoo.com.ar

https://orcid.org/0000-0003-2464-4671

\section{Centro de Estudios en Historia / Comunicación / Periodismo / Medios (CEHICOPEME) \\ Facultad de Periodismo y Comunicación Social \\ Universidad Nacional de La Plata | Argentina}

\section{Resumen}

El análisis de los editoriales publicados por La Nación durante los primeros cuatro años de la presente etapa democrática evidencian que el diario, que durante la última Dictadura (1976-1983) justificó las restricciones a la libertad de expresión, a partir del triunfo de Alfonsín manifestaría expectativas sobre la posibilidad de que se inaugurara una nueva tradición político-institucional liberal. Por ello, en esta materia, centró su atención en tres tópicos: la reforma de la Ley $\mathbf{2 2 . 2 8 5}$ de Radiodifusión, el cuestionamiento al Nuevo Orden Mundial de la Información y la Comunicación, y el rechazo a la ley de derecho a réplica.

Palabras clave

La Nación, Alfonsín, empresa, libertad de expresión

\section{Abstract}

The analysis of the editorials published by La Nación within the first four years of the current period of democracy prove that the newspaper, which justified the restrictions on freedom of expression imposed during the dictatorship (1976-1983), would arouse expectations of inaugurating a new liberal political-institutional tradition after the electoral victory of Alfonsín. Therefore, in this matter, this newspaper focused its attention on three topics: the amendment of Ley 22.285 de Radiodifusion, the questioning of the New Information Order and the rejection to the the right to reply law.

Keywords

La Nación, Alfonsín, company, freedom of expression 


\section{La Nación vs. Alfonsín}

\section{Preocupaciones empresariales \\ y libertad de expresión (1983-1987)}

Por César Luis Díaz y Mario Giménez

En el presente trabajo ${ }^{1}$ se examinan los editoriales que el diario argentino La Nación publicó entre diciembre de 1983 y diciembre de 1987 referidos a la libertad de expresión. Del universo de ciento ocho artículos se han escogido aquellos vinculados con las temáticas que en mayor número el medio jerarquizó durante ese lapso. Al respecto, podemos mencionar dos que había comenzado a tratar durante la última Dictadura: el Nuevo Orden Mundial de la Información y la Comunicación (NOMIC) y la Ley 22.285 de Radiodifusión, a las que sumó las normativas relacionadas con el accionar de los periodistas y los medios de comunicación durante la naciente democracia. Por estrictas razones de espacio, se excluyen los casos particulares de restricciones a la prensa.

Para comprender el comportamiento del matutino de la familia Mitre ${ }^{2}$ durante la democracia, resulta indispensable abrevar en los antecedentes, es decir en su postura durante la última Dictadura cívico militar (24/03/1976-10/12/1983). Por entonces, el diario, desde el rol de «actor político» (Borrat, 1989, p. 9), intervenía en el escenario institucional del país como «socio» ideológico de la Dictadura, a través del «periodismo hermesiano», y como «socio» económico, en virtud de la apropiación de la empresa Papel Prensa S.A. junto con sus colegas La Razón y Clarín (Díaz, Giménez \& Passaro, 2008).

Al construir sus agendas, los socios de La Nación solían tener una mirada sesgada que se ajustaba a la doctrina de la seguridad nacional, pues adherían a los valores «occidentales y cristianos». Con posterioridad, al asociarse con la Dictadura, el diario ejercerá un "periodismo hermesiano», ${ }^{3}$ constructo que ha posibilitado dar cuenta de la estrategia comunicacional instrumentada por el matutino que inducía a sus lectores/as a una 
interpretación de la realidad que invisibilizaba gran parte de los atropellos que cometía la administración dictatorial amparada en su proyecto de país. Esta noción analítica, asimismo, ha colaborado a visibilizar las «tergiversaciones» que este interesado socio efectuaba. Por caso, en ocasiones, La Nación apelaba a «mentiras sociales o a puntos ciegos»; en otras, recurría a «subterfugios» lingüísticos que, de un modo más sutil, alejaban a los lectores/as de la realidad (Díaz, 2011, p. 154).

En este artículo, se examinan los distintos estilos discursivos de los editoriales, en tanto herramienta válida para observar el posicionamiento del diario, según la propuesta de Raúl Rivadaneira Prada (1986), quien los clasifica en «expositivos, explicativos, combativos, críticos, apologéticos, admonitorios y predictivos» (pp. 227-229). Al respecto, también consideramos las «estrategias enunciativas, pues son ellas las que construyen la especificidad de la publicación» (Verón, 2005, p. 205) y han sido formuladas para un «destinatario genérico», para el cual se empleará el concepto «metacolectivo singular» (Verón, 1987, p. 18) y, en otro nivel, para tres subespecies de destinatarios: el prodestinatario, al que se apunta a través de mecanismos de fortalecimiento de la creencia compartida; el paradestinatario, blanco de mecanismos del orden de la persuasión; y el antidestinatario, blanco de las figuras de lo polémico (Verón, 2005).

De la retórica utilizada por el medio, nos detendremos en el empleo de los enlaces positivos, que son las «relaciones sintagmáticas que no alcanzan el estatus de sinónimos», y de los pares antagónicos, aquellos «pares originales que un análisis contrastativo debe destacar» (Maingueneau, 1989, p. 65); en la utilización de recursos tales como el principio de autoridad, que «permite deducir una conclusión de ese argumento sin necesidad de demostrar su verdad»; el de la ironía, donde «para demostrar que una tesis es falsa se utilizan a favor de ella argumentos absurdos que se atribuyen a defensores de esa tesis»; y el de la concesión, que «concede la palabra a un adversario real o ficticio aunque argumente en dirección opuesta para reforzar la imagen de objetividad de nuestra propia conclusión» (Ducrot, 1989, p. 140).

Estas herramientas teóricas ayudan a corroborar nuestra hipótesis que sostiene que, en general, La Nación no discontinuaría su discurso cuestionador frente a la Ley de Radiodifusión y al NOMIC, al tiempo que incorporaría a su agenda el proyecto de ley sobre el derecho a réplica con el propósito de malograr su aprobación. 
La Nación, mediante el ejercicio de un periodismo hermesiano, excluyó casi totalmente de su columna institucional la desaparición y el asesinato de periodistas, así como también la clausura de medios gráficos. Entre los temas que atendió durante el terrorismo de Estado, se encontraron: en el plano internacional, la propuesta de lograr un Nuevo Orden Mundial en la Información y la Comunicación (NOMIC), impulsada por la UNESCO y, en el orden local, la imposición de la Ley 22.285 de Radiodifusión, ${ }^{4}$ en ambos casos mediante una visión crítica, aunque en el segundo con escasa presencia editorial.

A partir de la recuperación transitoria de las Islas Malvinas, durante la gestión del tercer dictador, Leopoldo Galtieri, el diario viró respecto de su valoración editorial sobre la libertad de expresión, pues si entre el Golpe de 1976 y el 2 de abril de 1982 jerarquizó esta temática en una docena de ocasiones, entre el inicio de la conflagración en Malvinas y el to de diciembre de 1983 publicó cincuenta y cinco notas.

En el orden político, una vez producido el desembarco argentino en Malvinas, La Nación promovería la «unidad nacional» aunque excluyera de ella al peronismo y al comunismo (Giménez, 2015), posición que modificaría recién después de la derrota militar (Díaz \& Giménez, 2016). Consumada la rendición en Puerto Argentino, la eclosión de la crisis económica y social provocó un incremento exponencial en las medidas de fuerza impulsadas por el sindicalismo, que fueron repudiadas por el matutino por aducir que obedecían a motivos políticos (Díaz \& Giménez, 2017a); de resultas que su rechazo al peronismo y al sindicalismo lo llevó a persuadir a la opinión pública, en forma elíptica, de apoyar a Raúl Alfonsín, el candidato de la Unión Cívica Radical (UCR) (Díaz \& Giménez, 2017b) quien a la postre resultaría el triunfador en aquellas elecciones.

La derrota del peronismo, especulaba La Nación, podía inaugurar una nueva tradición político-institucional liberal, razón por la cual empleó su columna editorial para instar al metacolectivo sociedad a no confiar la suerte del país a líderes carismáticos o a caudillos populares (Díaz \& Giménez, 2018b). Para coadyuvar a este cometido, también entendía que debía despolitizarse la vida universitaria, a punto tal que rechazaba la participación del estudiantado en la discusión sobre los asuntos universitarios (Castro, 2018), así como en defensa de la República asumía una defensa irrestricta sobre la intangibilidad y, por ende, sobre la continuidad en democracia de los jueces que habían jurado respetar los estatutos del Proceso de Reorganización Nacional (Díaz \& López, 2018). 
El diario temía, además, que la crisis interna del peronismo elevara a la palestra al sindicalismo que, de ese modo, pudiera legitimarse como aglutinador de la demanda social dada la combatividad que venía manifestando desde finales de la Dictadura (Díaz \& Giménez, 2018a). De ahí que centrara su prédica en el aspecto normativo de la institucionalidad como pilar fundamental de la nueva tradición liberal que propiciaba y, en ese sentido, la legislación sobre medios de comunicación ocupó la mitad de los editoriales referidos a la libertad de expresión.

\section{Un reclamo permanente:}

reformar la Ley de Radiodifusión

Un dato decisivo a tener en cuenta son las contradicciones internas que imperaban en la administración gobernante y acaso el ejemplo más significativo sea el manifiesto enfrentamiento entre dos posiciones antagónicas. Una que propugnaba por la intervención del Estado en los asuntos atinentes al manejo de los medios de comunicación, sostenida por Leopoldo Moreau; y la otra, proclive a la privatización, que preconizaba Pedro Sánchez. El primero, a la sazón diputado nacional que presidía la Comisión de Medios de Comunicación de la Cámara Baja, decía del segundo, responsable del Comité Federal de Radiodifusión (COMFER): «No piensa como la plataforma partidaria» sino como «hombre del Proceso» (Blaustein, 2013, p. 156). Certera objeción para Sánchez que, efectivamente, se había desempeñado al frente de la Secretaría de Información Pública de la provincia de Chubut, entre 1977 y 1978 (Blaustein, 2013).

El diario de los Mitre, teniendo en consideración estas desavenencias políticas, interpelaría tempranamente a la gestión radical como paradestinatario, y manifestaría su rechazo en el editorial titulado: «La ley de radiodifusión y el nuevo gobierno» $(28 / 12 / 1983){ }^{5}$ La nota, de estilo admonitorio, elogiaba, mediante el recurso de la concesión, al delegado del COMFER por haberse comprometido a revisar las licitaciones tramitadas, aunque también reclamaba que se hiciera lo propio con la norma bajo la cual se produjeron, porque su «espíritu discriminatorio e inconstitucional [...] pretende negar a las empresas periodísticas la oportunidad de extender y complementar y aun transformar sus servicios actuales» (28/12/1983). Casi un año después, otra alocución del delegado normalizador del COMFER daría pábulo al optimismo del medio examinado que, a pesar del tiempo transcurrido, celebraría mediante una nota apologética: 
[...] es alentador, también, que recientemente se haya expresado [en pos de] garantizar a todo ciudadano y a todo grupo empresario nacional la posibilidad de tener acceso -sin discriminaciones ni privilegios de ningún tipo- a la titularidad de las licencias para la prestación de servicios de radiofonía y de televisión (10/o9/1984).

Para remarcar la coincidencia, elogiaba su apreciación sobre la inconstitucionalidad del artículo 45 de la Ley de Radiodifusión, al tiempo que acotaba que esa norma discriminatoria era «contraria a la libertad de expresión que privilegia como un dogma el radicalismo» (10/o9/1984). El matutino se expresaba como representante del metacolectivo ciudadano y también de las empresas, escogía como paradestinatario al oficialismo y, expresándose de modo autorreferencial, enfatizaba: «Desde estas columnas denunciamos muchas veces [ese] inaceptable mecanismo de discriminación» (10/o9/1984), cuando en realidad solo lo había hecho en dos ocasiones, durante la Dictadura y a poco de asumir Alfonsín. En tanto, se presentaba como guardián de la institucionalidad, al subrayar su «defensa de la democracia y de la libertad de expresión» (10/og/1984) y, por ello, interpelaba al radicalismo gobernante confrontándolo con su propia doctrina.

La asunción del nuevo secretario de Información Pública de la Nación, Juan Radonjic, que reemplazó a Emilio Gibaja, también se convertiría en una buena excusa para que, mediante el recurso de la concesión, el medio reconociera:

Si bien el gobierno que inició su gestión en diciembre de 1983 se ha mostrado hasta ahora respetuoso de la libertad de información, corresponde señalar que en más de una oportunidad funcionarios políticos pertenecientes a las filas del partido gobernante se han pronunciado en favor de la implantación de sistemas reñidos con la plena vigencia de esa $\operatorname{libertad}^{6}[\ldots]$ destinados a controlar o «regular» la labor de los órganos de información privados (15/05/1985).

Por ello, con estilo admonitorio, dirigiéndose al gobierno nacional como paradestinatario, reclamaba que se «elimine definitivamente la absurda proscripción consagrada por el artículo 45 de la Ley de Radiodifusión» (15/05/1985).

La realización de la Asamblea General de la Asociación Internacional de Radiodifusión $(\mathrm{AIR})^{7}$ en Buenos Aires fue jerarquizada en una nota admonitoria en la cual el diario empleaba como principio de autoridad a Luis Borgerth -representante de la red O'Globo 
de Brasil- quien había afirmado: «El acceso a la radiofonía y a la televisión debe estar abierto a todas las empresas, sin exclusiones»y, en referencia a la normativa vigente en nuestro país, había señalado: «Tal prohibición "es anacrónica” (13/06/1985). Confrontando con la gestión radical, La Nación recordaba: «El Gobierno se ha comprometido a revisar dicha norma, aunque nada indica que se esté cerca de esa decisión» (13/06/1985). De ahí que, con estilo admonitorio, exigiera «poner decididamente en marcha los mecanismos legales y administrativos correspondientes para que se lleve efectivamente a término la tarea prometida» (13/06/1985). Demanda, a todas luces, extemporánea, pues en la plataforma electoral la UCR se comprometía a «la creación de tres sistemas para la explotación de la radio y la televisión: el reservado al Estado, el reservado a la gestión privada y el reservado al ente autónomo de derecho público no gubernamental» (UCR, 1983), pero nada decía de modificar la Ley 22.285 para permitir que las empresas propietarias de medios gráficos pudieran acceder a la titularidad de los medios audiovisuales.

La demora en la adjudicación de estos últimos dio lugar a que en diversas provincias se tomaran decisiones legislativas a tal efecto. Por caso, los legisladores neuquinos declararon de jurisdicción provincial los servicios de radio y televisión con asiento en ese territorio, ante lo cual, si bien el matutino coincidía con el delegado normalizador del COMFER en su «inconveniencia», aprovechaba para cuestionar la vigencia de la Ley 22.285 $\mathrm{y}$, dirigiéndose al paradestinatario encarnado por el metacolectivo argentinos, explicaba que «lo que debe preocupar a los argentinos es que la radio y la TV sean la resultante del libre juego, sin discriminaciones de la iniciativa privada» (12/01/1986); así como también, después de hacer gala de su ideología liberal, interpelaba al paradestinatario Estado nacional a quien le hacía notar: «Lo urgente es encarar sin más demoras la sanción de la nueva Ley Nacional de Radiodifusión [así como también] deberá reanudarse el proceso de privatización -hoy interrumpido- de las emisoras que el Estado aún retiene en su poder» $(12 / 01 / 1986)$.

A su vez, cuando «funcionarios del gobierno de Catamarca y legisladores justicialistas de esa provincia» anunciaron que impulsarían una ley con idénticos fines, el diario tomaría como principio de autoridad a la Corte Suprema de Justicia que, ante la ley neuquina, había dictado «una medida de no innovar» con lo cual, su aplicación quedó inhibida. Con estilo admonitorio, reiteraba que solo una modificación de la Ley de Radiodifusión, como se ha «reclamado insistentemente desde estas columnas y sin discriminaciones o exclusiones de ninguna clase»(o1/o2/1986), podrá evitar conflictos de esta índole. 
La inacción del gobierno nacional y la voluntad de ciertas provincias de tomar intervención directa en la regulación de medios de comunicación, darían lugar a una nota en la que el medio volvía a recurrir como principio de autoridad al órgano máximo del Poder Judicial de la Nación que había ratificado la vigencia de la Ley 22.285 y dispuesto, por ello, que el «Poder Ejecutivo Nacional notifique al gobierno de la provincia de Formosa para que ordene de inmediato el cese de las emisiones del Canal 3 de televisión y de Radio Tropical, en frecuencia modulada» (03/08/1987).

Ante tanta iniciativa provincial, el matutino se dirigió admonitoria e imperativamente al Parlamento para que pusiera fin a «la situación de desorden e injusticia a que se ha llegado en el campo de la radiodifusión» (03/08/1987). En esa misma nota, apelaba al principio de autoridad de las corporaciones empresariales, en este caso la Asociación de Televisoras Argentinas (ATA), para sentenciar que «si no fuese por las trabas que impone el poder político, no se plantearía el caso de los medios clandestinos que se amparan en la necesidad de satisfacer las necesidades de comunicación [...] en General Roca, Catamarca y Tres Arroyos» (03/o8/1987).

Las expectativas reformistas que La Nación venía enfatizando, en ciertos momentos avaladas por las del titular del COMFER, se desvanecerían al promediar el tercer año de gobierno e ingresarían en un camino sin retorno cuando Radonjic anunció que los medios controlados por el Estado no serían privatizados. Estos dichos provocaron la reacción del diario que, asumiendo la representación del metacolectivo «opinión pública democrática», volvió a expresar su categórico rechazo a la ley y, mediante el recurso de la analogía, equiparó «el restablecimiento de las instituciones democráticas [con] la liquidación del enorme aparato de difusión del Estado»(31/10/1986). Seguidamente, hacía notar el «desaliento» que le provocaba la gestión radical al no promover la reforma apelando a una serie de enlaces positivos para descalificar la norma como una «distorsión que entraña la subsistencia de una herramienta de poder» (31/10/1986).

Al comenzar el cuarto año de la gestión alfonsinista, el diario pondría en evidencia las «Promesas incumplidas sobre radiodifusión»(09/01/1987), tal como rezaba el título de una columna crítica en la cual afirmaba:

Al borde del plazo previsto, el Consejo para la Consolidación de la Democracia informó que el presidente de la Nación solicitó a ese cuerpo asesor un informe sobre dicha iniciativa y que, en consecuencia, se iniciarán consultas a empresarios y especialistas en medios de comunicación, con vistas a la futura ley (og/o1/1987). ${ }^{1}$ 
La Nación desestimaba este anuncio pues lo consideraba parte de las medidas dilatorias que venía ensayando el poder ejecutivo, al tiempo de informar que la Secretaría de Comunicaciones había elaborado, junto con la de Información Pública, «una propuesta» sobre el tema que sería sometida «en breve» a la consideración del Presidente, lo cual venía a confirmar «la morosidad del trámite» (o9/o1/1987). Al parecer, a La Nación, antes que la confrontación de opiniones sobre este asunto, le interesaba la celeridad del trámite burocrático. No obstante, ambas declaraciones parecieron alumbrar un tiempo de reforma por lo cual, con optimismo predictivo, la siguiente columna se titularía «La futura Ley de Radiodifusión» (24/02/1987).

Su estilo admonitorio volvería a tomar como principio de autoridad a Alfonsín para celebrar «los reiterados llamados del Presidente a reducir el intervencionismo estatal, a desregular la actividad de los distintos sectores de la vida nacional y a promover el crecimiento del sector privado» (24/02/1987), pero confrontándolo, por medio del par antagónico, con las distintas medidas ensayadas por el PEN que no iban en ese sentido. Asimismo, fustigaba el proyecto presentado por el Consejo Asesor para la Consolidación de la Democracia, pues disponía que «los poderes públicos velarán por el pluralismo y la objetividad informativa [que] podría convertirse en una excusa legal capaz de justificar la eventual intromisión del poder público en el manejo de los medios de información privados» (24/02/1987). Ante lo cual el matutino, fiel a su ideología liberal, sentenciaba que esas particularidades «deben ser reguladas por la decisión autónoma de cada medio $\mathrm{o}$, en todo caso, por las leyes del mercado [...] o se avanza hacia un paternalismo intervencionista del Estado de imprevisibles consecuencias» (24/02/1987).

Resulta elocuente que todo el arsenal retórico desplegado por La Nación para acelerar la sanción de una nueva norma sobre medios de comunicación no encontrara eco en el gobierno. Entonces, cuando se dio a conocer el «Anteproyecto sobre la ley de radiodifusión», presentado por el Consejo Asesor para la Consolidación de la Democracia, mediante un mensaje crítico, reiteraría sus cuestionamientos acerca del absurdo de garantizar la libertad de expresión con una ley cuando había sido establecida por la Constitución hacía ciento treinta años. Además, la impugnaba pues, «con la intención de evitar presuntos monopolios informativos» (25/11/1987) insistía en imponer restricciones para que los órganos gráficos accedieran al control de las emisoras radiales y televisivas limitando «a un tercio del capital la participación accionaria que los dueños de periódicos pueden tener en empresas licenciatarias de ondas de radio o de TV, a menos que estas ondas cubran áreas en las cuales la circulación de tales periódicos no 
sea significativa» (25/11/1987). En ese sentido, concluía: «[El anteproyecto examinado] sigue promoviendo la discriminación, que va en desmedro de los medios de comunicación escrita y del desarrollo de un sistema de comunicación moderno y capaz de contribuir eficazmente al afianzamiento de la democracia» (25/11/1987).

\section{Una nueva batalla: el derecho de réplica}

La denominada ley de «derecho de réplica», destinada a beneficiar a quien se sintiera damnificado por la información o la opinión vertida en un órgano de prensa, fue otra iniciativa que motivaría la preocupación del matutino. El proyecto, presentado por el senador radical Ricardo Lafferriere, fue criticado mediante la figura del par antagónico, contraponiéndolo con la historia de la UCR, razón por la cual su aprobación le parecía «poco probable por la tradición que en esta materia caracteriza al partido gobernante» (21/07/1985).

Para demostrar la magnitud de la reprobación, tomaba como principio de autoridad a la Asociación de Entidades Periodísticas Argentinas (ADEPA), ${ }^{8}$ que explicaba que la norma era innecesaria pues «la legislación vigente en la Argentina tiene previstos los caminos para sancionar los delitos que se puedan cometer por medio de la prensa oral o escrita» (21/07/1985); haciendo lo propio con la Sociedad Interamericana de Prensa (SIP), que sentenciaba: «No hay delitos de prensa». También fundaba su rechazo mediante la apelación a los artículos 14 y 32 de la Constitución Nacional y, valiéndose del recurso de la ironía, trataba de convencer al paradestinatario de que al habilitar al replicante a presentar «por sí mismo o por "su representante" el texto que desee, [...] abre un sinfín de alternativas incontrolables y que pueden llegar a generar situaciones insólitas» (21/07/1985). Como agravante, apuntaba que aun reconociendo al damnificado el ejercicio del derecho a la «réplica» la controversia no quedaría finiquitada pues se establecía que este podría iniciar reclamos de «naturaleza civil o en la instancia penal» (21/07/1985).

También la $41^{\circ}$ Asamblea General de la SIP le permitiría a La Nación volver sobre este tema en una nota expositiva, en la cual tomó como principio de autoridad el testimonio brindado por José Dutríz, de La Prensa Gráfica, de El Salvador, «quien refirió los graves perjuicios que causó en su país el establecimiento del derecho de réplica, y afirmó -a la luz de la experiencia recogida- que lo relativo a esa materia no debe ser regulado por ley alguna» (27/10/1985). 
A su vez, en una columna destinada a cuestionar la acumulación de medios de comunicación en la órbita del Estado, contraponía la inacción parlamentaria en materia de privatización de medios estatales con iniciativas presentadas en el Congreso de la Nación. En este caso, omitiendo mencionar al senador Lafferriere, exponía con ironía: «Quizás algún parlamentario de la bancada oficial pretendió desviar la atención de la ciudadanía sobre el monopolio radiotelevisivo, "redescubriendo" el mal llamado derecho a réplica» (01/11/1985).

El comienzo de la segunda mitad del período analizado coincide con el importante apoyo que el gobierno cosechó en las elecciones legislativas. El diario, lejos de conciliar posiciones con una gestión refrendada en las urnas, decidió redoblar el esfuerzo retórico en esta disputa, cuando por caso, fue aprobado el «derecho de réplica» en Río Negro. Con estilo crítico, denunció la ley como «una grave lesión a la libertad de prensa» (26/02/1986) que, además, afectaba las finanzas de las firmas periodísticas, pues «prevé la posibilidad de que el juez aplique a la empresa editora una multa diaria [...] y se faculta asimismo al magistrado judicial a disponer la publicación de la réplica en otro medio periodístico "a costa del editor responsable del medio condenado"» (26/02/1986).

Similar reacción produciría, poco después, la incorporación de esta garantía a la Constitución provincial de Santiago del Estero, ${ }^{9}$ a la cual también destinaría una nota crítica apelando al principio de autoridad autorreferencial y de la SIP: «Dijimos también -y hay que repetirlo- que la multiplicación de proyectos sobre tal materia demuestra que ideologías contrarias a la democracia se están abriendo paso en nuestro país en el seno de las fuerzas políticas mayoritarias» (12/03/1986). A estos casos, sumaría otros de «orientación coincidentes [que] están en trámite, además, en La Rioja, en Salta y en Jujuy» (12/03/1986). Ante el efecto cascada, volvería a centrar su crítica apelando al principio de autoridad de la Constitución y, como si rehusara a la posibilidad de permitir el contrapunto de pareceres en la superficie redaccional de los órganos gráficos, enfatizaba con estilo predictivo:

[Esta legislación] hará que la mayor parte de las informaciones, comentarios o notas, difundidos por la prensa escrita o por otros medios, dé lugar a la difusión de réplicas, descargos, aclaraciones o interpretaciones de cada una de las personas que se sientan «afectadas» -término impreciso y de extraordinaria amplitudpor la publicación original (o6/04/1986). 
Entonces, escogiendo como paradestinatario al oficialismo, manifestaba en tercera persona el asombro que le provocaba que «los representantes del partido radical impulsen o apoyen este tipo de decisiones», al tiempo que les llamaba la atención con estilo admonitorio: «La democracia exige asumir los riesgos de la libertad; el cercenamiento de la libertad de prensa es un paso fundamental hacia esquemas totalitarios» $(06 / 04 / 1986)$.

La realización de la $35^{\circ}$ Asamblea del Instituto de Prensa Internacional (IPI) le permitió, nuevamente, controvertir el «derecho de réplica». Si bien en los últimos doce años nunca había jerarquizado editorialmente a esta organización, su mensaje apologético la calificó como un «importante foro internacional» de cuyas conclusiones se valió para titular el editorial «Condena mundial al derecho de réplica» (o1/o6/1986). ${ }^{10}$ En ese sentido, destacó la labor de la representación argentina (editores y periodistas) cuyos integrantes presentaron «argumentos irrefutables» para fundamentar la «condena» ecuménica.

En otro orden, llama la atención que destacara como uno de los temas que absorbió el interés de los participantes

[...] el que se refiere al significado del concepto de seguridad nacional y a los límites que en función de ese concepto se pretende fijar a veces a la tarea informativa. Diversas voces coincidieron en señalar que esas expresiones han sido casi siempre usadas por los regímenes dictatoriales para cercenar la libertad de expresión (o1/06/1986).

Al parecer, en tiempos democráticos el diario La Nación se permitía problematizar la doctrina que lo había inspirado para ejercer el periodismo hermesiano durante la Dictadura.

La estrategia enunciativa de fortalecer sus opiniones a partir de recurrir al principio de autoridad de entidades corporativas de las comunicaciones se puede apreciar cuando las Jornadas de la Comisión Empresaria de Medios de Comunicación Independientes $(\mathrm{CEMCI})^{11}$ merecieron la jerarquización editorial del matutino. La nota, de estilo apologético, destacaba como principio de autoridad

El análisis que distinguidos juristas argentinos hicieron de los proyectos que pretenden implantar en el país el llamado derecho de réplica [que] dejó como saldo una total coincidencia respecto de la necesidad de desregular esas actividades y de limitar al mínimo la intervención del Estado (29/08/1986). ${ }^{12}$ 
Haría lo propio, al expresar su crítica en la primera persona del plural ante «los proyectos sobre pretendidos "derechos de réplica", que hemos rechazado y denunciado en su verdadero sentido intimidatorio, posición en la cual nos acompañan la ADEPA, la AEDBA y la CEMCI, así como la $\operatorname{SIP}^{13}$ y el IPI» (19/o9/1986).

La insistencia de los funcionarios nacionales y provinciales en poner en vigencia el derecho que aquí analizamos, sin duda, terminó por colmar la paciencia del centenario matutino, que ya se consideraba en las antípodas del gobierno alfonsinista respecto de su vínculo con los medios. En este sentido, incorporó a su estrategia enunciativa el cuestionamiento a la legitimidad del origen del gobierno radical consagrado en 1983. Para conferir impacto a sus conceptos, exaltaba en nombre del «esfuerzo» de todos, representados en el metacolectivo «el país», que se encontraba en las antípodas del accionar del gobierno en el cual veía resurgir «las tendencias autoritarias e intervencionistas que se enseñorearon de la vida argentina en las últimas décadas» (11/05/1987), explicando que el partido radical había llegado «al poder por el voto de una mayoría ciudadana que más allá de su adhesión a un hombre y a un partido quiso señalar, tres años atrás, su adhesión a la democracia, que sin libertad de prensa es imposible» (11/05/1987).

La profundización de su disconformidad se haría notar cuando tres años y medio después expuso que desde diciembre de 1983 se observaba en el PEN un «afán de intervención ilegítima en los medios de comunicación» amparado en el «uso indebido de la palabra “democratización”» (02/06/1987). La pluma del editorialista, recogiendo la tradición del órgano fundado por Bartolomé Mitre, haría notar que el gobierno, con «habilidad dialéctica», pretendía apropiarse de palabras de «alto contenido emocional esgrimidas como banderas convocantes [tales como] la palabra democracia» (o2/06/1987). Es entonces cuando, amparado en «la experiencia histórica», advierte al público como paradestinatario, que «detrás de estas grandes declaraciones se agazapan, a veces, intenciones absolutamente opuestas a su recto sentido» (02/06/1987). En ese orden recurre a una analogía inaplicable para el caso argentino y advierte que «las dictaduras marxistas instaladas en el mundo contemporáneo suelen denominarse a sí mismas como "repúblicas democráticas y populares"» (02/o6/1987).

Para fortalecer su estrategia confrontativa, cuestionaría la posibilidad de que el Estado alcanzara, además del control de los medios audiovisuales, el de «los diarios independientes [en virtud] de los proyectos aprobados o en tren de aprobarse sobre 
el mal llamado derecho de réplica»(02/06/1987). De ahí que, como si fuera una consecuencia lógica, predecía que de la aplicación de ese derecho sobrevendría una verdadera catástrofe, solo evitable si se producía una reacción

[...] de toda la sociedad, pues si por comodidad, indiferencia o incomprensión deja perder la libertad de prensa comprenderá luego -aunque ya sea demasiado tarde- que ha perdido también la libertad integralmente concebida. No hay democracia sin libertad; no hay libertad sin libertad de prensa; no hay libertad de prensa sin propiedad privada de los medios de difusión y no habrá propiedad privada de los medios de difusión si se instalaran en su seno verdaderos "soviets" que pretendieran conducirlos y dictarles lo que deben informar, lo que deben opinar y lo que pueden publicar (02/06/1987).

El dramatismo de esta predicción, por la crudeza de los términos expresados, se puede equiparar al que, con similar objetivo, había manifestado bajo el imperio de la doctrina de la seguridad nacional durante la Dictadura (1976-1983). En definitiva, el empeño manifestado por el gobierno radical en sancionar una ley nacional y su concreción en las provincias gobernadas por los partidos de la oposición, cimentarían la desazón del diario, que, en otro mensaje autorreferencial y predictivo, expresaba que «la imposición del mal llamado derecho de réplica respecto de las notas o artículos de opinión, significaría, lisa y llanamente, condenar a muerte al periodismo libre e independiente» (10/08/1987). ${ }^{14}$

Después de un año y medio de intenso batallar para impedir que se consumara el derecho de réplica como parte del cuerpo normativo en el país, el cierre del cuarto año del gobierno radical le depararía una semana en la cual pasó de la crítica, basándose en el principio de autoridad de la ADEPA, la SIP y el IPI para rechazar la aprobación de ese derecho en la Legislatura del Chubut (10/12/1987), a la apología, solo 72 horas más tarde, al celebrar que el gobernador saliente, el radical Atilio J. Viglione, vetara «la ley denominada de "Derecho de respuesta"» (13/12/1987). Tal como puede apreciarse, poco le interesaba al matutino abrevar sobre la representatividad que avalaba a un gobernante a punto de transferir el mando para rubricar un decreto que favorecía sus intereses. 
La Nación batalló contra este proyecto desde la última Dictadura, encontrando en democracia una continuidad palmaria. Por caso, ante el apoyo brindado por la UNESCO a la creación de la Agencia Latinoamericana de Servicios Especiales de Información (ALASEI) $)^{15}$ como parte del NOMIC, el diario enfatizaba de manera autorreferencial: «Más de una vez nos referimos en estas columnas a la grave amenaza que se cierne sobre la libertad de prensa como consecuencia de tales proyectos»(30/12/1987). Por lo cual, con un mensaje predictivo, presagiaba que mediante la aplicación de controles estatales, «por mínimos que sean, no tardan en prosperar el discrecionalismo, la arbitrariedad, el autoritarismo y la concentración totalitaria del poder» (30/12/1983).

El diario hacía pública su defensa del sistema democrático, por medio de una retórica construida con el fin de desbaratar los argumentos de los defensores del NOMIC quienes, bajos los postulados de «mejorar la circulación de las informaciones [y de] procurar que esas informaciones no dependan sólo de las grandes agencias internacionales, genéricamente acusadas de estar al servicio de los intereses capitalistas e imperialistas» (04/o1/1984), intentaban obtener consenso entre «los hombres de buena voluntad pero mentalmente desprevenidos» quienes, a su vez, víctimas de esa prédica, terminarían por aceptar que para salvarse «de esos amos perversos, como ocurre en los regímenes socialistas y comunistas, se acuda al Estado; éste, protector y paternal, se ocupará de que la circulación de las informaciones sea mejor, más abundante y mejor orientada ideológicamente» (04/o1/1984).

De este modo, recuperaba conceptos de la doctrina de seguridad nacional y profería con estilo admonitorio que se afrontaba una batalla a escala planetaria, en la cual otorgaba el principio de autoridad a «los Estados Unidos [que] advirtieron, con razón, la desviación ideológica de la UNESCO [...]. ${ }^{16}$ El mundo libre debe evitar que le ocurra lo mismo con respecto a la libertad de prensa en general» (04/o1/1984). Como puede apreciarse, en este tema, el diario omitía el abismo que separaba a la Dictadura de 1976-1983 de un país gobernado por quienes representaban al pueblo.

Otra reafirmación de su coherencia ideológica occidental quedó evidenciada en su compromiso para combatir las iniciativas de los países del Tercer Mundo, en este caso, al rechazar la influencia que estas jóvenes naciones podían ejercer sobre potencias del mundo Occidental. Mediante una nota crítica, titulada sin ambages «Censura de prensa 
en Francia» (16/03/1984), ${ }^{17}$ rechazaba de plano la aprobación en ese país de la que denominaba una ley de control de la prensa. A su vez, reafirmaba de manera autorreferencial su lucha contra el NOMIC: «Muchas veces dijimos -y lo repetimos no hace mucho- [que] la pretensión de imponer un "nuevo orden informativo", [...] sea cual fuere la causa que se invoque para justificarlo, lleva en si el germen de la destrucción del principio que ampara la libre expresión» (16/03/1984).

En esta oportunidad, volvía a aceptar el liderazgo de las potencias occidentales al plantear con estilo predictivo: «Lo que ocurra en Francia tendrá, obviamente, hondas consecuencias para la causa de la libertad de prensa en otras latitudes» (16/03/1984). Al diario le resultaba imposible admitir que la integración a las Naciones Unidas de numerosas nuevas nacionalidades, «de dimensiones absurdamente pequeñas, denominadas genéricamente "subdesarrolladas" o también del "tercer mundo"», mediante la incorporación de «funcionarios, expertos o asesores con antecedentes de orientación marxista o, al menos, muy poco dispuestos a hostilizar a esa orientación», hubiera podido hegemonizar los debates en la UNESCO mediante «una metodología más sutil y engañosa [...]. Idéntica tarea se desarrolla en diversos países y nada raro sería que, en corto lapso, estrategias y argumentaciones similares se instalen entre nosotros. Los enemigos de la libertad son hábiles para escudarse detrás de la bandera de su defensa» $(30 / 10 / 1984)$.

El diario, convencido de que el objetivo del nuevo orden informativo era destruir a las empresas periodísticas privadas, volvía a expresarse desde la autorreferencialidad y advertía: «Muchas veces nos referimos desde estas columnas a las amenazas que se ciernen contra la libertad de prensa» (07/03/1985). Mediante el principio de la concesión, y en nombre de un metacolectivo unánime, reconocía: «Nadie pone en duda la conveniencia de promover en todas las naciones del mundo el establecimiento de una infraestructura informativa moderna y eficiente», al tiempo que consideraba «lamentable que el secretario de Información Pública haya declarado [...] que se trata de un proyecto saludable [pues] tales declaraciones resultan incompatibles con la reconocida filiación democrática del gobierno que inició su gestión en diciembre de 1983» (07/03/1985).

Como se puede apreciar, el medio eludía un enfrentamiento directo con el Presidente y hasta con la UCR, al confrontar con sus colaboradores, a quienes descalificaba: 
Con desconcierto y extrañeza la opinión pública asiste [...] a la campaña que algunos funcionarios políticos [sostienen, pues,] curiosamente, está reñida no sólo con los sanos principios del republicanismo democrático y de la Constitución Nacional, sino también con la permanente prédica en defensa de la libertad de expresión que ha sido uno de los rasgos históricos tradicionales del partido en el que militan (07/05/1985).

Entonces, citando a la entidad que representaba a los diarios de Buenos Aires como principio de autoridad, enunciaba:

Como dijo acertadamente AEDBA, «se hace necesario comprender que la democracia y el bien común no son patrimonio de ningún gobierno [...] y la prensa independiente argentina constituye uno de los grandes intérpretes entre el Gobierno y la ciudadanía. Permitir que sea limitada o regimentada es limitar o regimentar a los propios ciudadanos, ya que la libertad de prensa se origina en la soberanía del pueblo» (07/05/1985).

Afirmación de la cual se puede colegir que sin medios de comunicación privados no habría vínculo entre el pueblo soberano y sus representantes y, por ende, no habría democracia.

El matutino recién involucraría en esta controversia al presidente de la Nación al citar sus palabras en la apertura de las Jornadas de la CEMCI, cuando su mensaje adoptó un tono liberal: «Creo que todos coincidimos en que una sociedad democrática y pluralista no lo es enteramente si no rige la más absoluta libertad de prensa» (29/08/1986). No obstante, cuando el propio Alfonsín -en términos similares a los proclamados por el NOMIC-, se manifestó a favor de «una circulación más equilibrada de la información» en el mundo, el matutino no dudó en enmendarlo al señalar que esas observaciones «debieron haberse completado con la aclaración de que en ningún caso se intentará corregir esos desequilibrios mediante la intervención del Estado» (29/08/1986). Definición que reafirmaría mediante un mensaje autorreferencial, complacido porque en las Jornadas se convalidó «la idea varias veces expresada en estas columnas de que tal proyecto constituye una grave amenaza a la libertad de prensa. La idea de un nuevo orden debe ser rechazada de plano» $(29 / 08 / 1986) .^{18}$ 
Al promediar el cuarto año del gobierno radical, en plena campaña electoral, La Nación ya no tendría indulgencia alguna con las políticas comunicacionales. De ahí el mensaje con el cual interpelaba al PEN como antidestinatario y señalaba, con estilo crítico y lapidario, que desde diciembre de 1983 el radicalismo había demostrado un «afán de intervención ilegítima en los medios de comunicación», amparado en el «uso indebido de la palabra "democratización"»(02/06/1987). Así, dirigiéndose a quienes habían confiado en la UCR como paradestinatarios les haría notar que el partido había hecho uso de la «habilidad dialéctica [que] reside en la apropiación de palabras de alto contenido emocional esgrimidas como banderas convocantes [como] la palabra democracia» (02/06/1987).

Esta preocupación mutaría a un optimismo moderado cuando, a partir del cambio de autoridades que se produciría el 7 de noviembre de 1987, el diario aventuraba el inicio de una nueva etapa en la UNESCO. Como era habitual en esta columna, la historia se volvía principio de autoridad $\mathrm{y}$, por ello, reclamaba admonitoriamente que ese organismo debía volver a los objetivos proclamados durante su creación, en 1946, y concluir con el «crecimiento burocrático, que se fue cristalizando en una presencia cada vez más numerosa de funcionarios, expertos y asesores de predominante orientación marxista» (11/o9/1987).

Estos conceptos serían reiterados en un mensaje autorreferencial jactancioso, pues, desde sus columnas, «se desenmascaró el proyecto del NOMIC, destinado a posicionar un sistema que, en la práctica, habría de terminar en una prensa sometida al poder de los gobiernos» (23/10/1987). Curiosamente, citaba como punto de inflexión el inicio de la posguerra mundial, al tiempo que, sin vacilar, apelaba al lenguaje belicista para continuar con la confrontación contra el NOMIC, cuyo objetivo era

[...] ganar la mente del individuo en la guerra de la información, entre los que quieren controlarla a través de agencias gubernamentales y los que defienden el libre flujo informativo. La prueba es que no obstante el tiempo transcurrido y el dinero invertido en la creación de nuevas agencias en el Tercer Mundo ninguna de estas es privada y todas están vinculadas con gobiernos (27/11/1987).

De este modo, insistía en su incesante «batalla» contra el Estado, sobre todo, si este era de un pequeño país «tercermundista». 


\section{Reflexiones finales}

La Nación, como un potente «actor político», que en este caso defendía de manera consecuente su posición ideológica, no discontinuaría la construcción de sentido asumida durante la Dictadura, fustigando dos temas, a su entender, muy caros a la libertad de expresión: la Ley 22.285 de Radiodifusión -y, especialmente, el artículo 45- y el NOMIC.

En ese sentido, se debe destacar, que transcurridos muy pocos días de que el gobierno democrático asumiera, desde su sección institucional el diario instrumentaría toda una arquitectura discursiva para criticar al NOMIC. En efecto, lo cuestionó sin solución de continuidad desde 1976. Mediante el empleo de conceptos de la doctrina de seguridad nacional que eran habituales durante la dictadura proponía plantear una batalla a escala planetaria que sostuvo, incluso, cuando el cambio de autoridades en la UNESCO auguraba una marcha atrás en esta política. Asimismo, exigió la reforma de la Ley 22.285 para que los medios gráficos pudieran acceder a la titularidad de las empresas audiovisuales que debían privatizarse.

El matutino de la familia Mitre pergeñaría una modalidad de «desgaste» del alfonsinismo hostilizando, sobre todo, a sus funcionarios, de quienes, además, explotaba discursivamente sus diferencias políticas, en los casos de quienes se hallaban al frente de secretarías, medios oficiales, diputados, etc., pero preservando la figura del presidente. Sin embargo, en una coyuntura cargada de tensiones, no trepidó en criticar a Alfonsín -símbolo indiscutido de la democracia- al solo efecto de llevar su tesitura hasta las últimas consecuencias. Esta particularidad, sumada a la tercera hipótesis planteada en torno del proyecto de ley de «derecho de réplica» impulsado por el senador Lafferriere, constituyó uno de los temas inherentes al período democrático. Así, confrontó con esta iniciativa legislativa de cuño democrático, cuya aprobación, llegó a predecir, podría terminar con la prensa privada y por ende con la democracia.

La Nación recurrió con frecuencia a la estrategia enunciativa de fortalecer sus opiniones mediante la apelación al principio de autoridad de la Constitución Nacional, a sus propios editoriales -aun exagerando o falseando la dimensión de sus intervenciones-, así como a las entidades corporativas que representaban al empresariado de las comunicaciones (ADEPA, AEDBA, CEMCI, IPI, SIP) para apoyar sus objeciones. 
Por último, el matutino siempre fundaba sus cuestionamientos o sus aportes sobre los tres temas abordados con el objetivo de garantizar la libertad de expresión como un valor sustantivo en relación con el fortalecimiento de la institucionalidad democrática, conforme su particular manera de percibirla, es decir, desde una posición liberal conservadora que solía defender más a las empresas privadas que al bien común.

\section{Referencias}

Basombrío, M. C. (2017). Discurso político y prensa escrita durante el alfonsinismo (1987-1989). Improntas de la comunicación y la cultura, (5). Recuperado de https://doi.org/10.24215/24690457eo21

Blaustein, E. (2013). Días de rabia. El periodismo, los medios y las batallas del kirchnerismo. Ciudad Autónoma de Buenos Aires, Argentina: Ediciones B.

Borrat, H. (1989). El periódico, actor político. Barcelona, España: Gili.

Castro, M. (2018). El discurso editorial de La Nación sobre la universidad en el primer año de la recuperación democrática (10/12/83). Actas de Periodismo y Comunicación, 4(3). Recuperado de https://perio.unlp.edu.ar/ojs/index.php/actas/article/view/5441

Com, S. (2009). El alfonsinismo, contexto sociopolítico y medios de comunicación (pp. 189-214). En G. Mastrini (Ed.), Mucho ruido, pocas leyes. Ciudad Autónoma de Buenos Aires, Argentina: La Crujía.

Díaz, C. (2011). La Nación y Clarín frente a la violencia política 1976-1980. Dos casos de periodismo hermesiano. En J. Saborido y M. Borrelli (Comps.), Voces y silencios: la prensa argentina y la dictadura militar (1976-1983) (pp. 153-180). Ciudad Autónoma de Buenos Aires, Argentina: Eudeba.

Díaz, C. y Giménez, M. (2016). La Nación y Clarín: dos propuestas para la democratización y reinserción en occidente a propósito de la guerra de Malvinas. Revista Observatorio, 2(1), 194-229. Recuperado de https://doi.org/10.20873/uft.24474266.2016v2nip194

Díaz, C. y Giménez, M. (2017a). La Nación y el sindicalismo en 1983: la crisis, las huelgas y la democratización. Revista Internacional de Historia de la Comunicación, (9), 92-107. Recuperado de http://dx.doi.org/10.12795/RiHC.2017.iog.04 
Díaz, C. y Giménez, M. (2017b). En busca de la «República Verdadera»: La Nación construyendo la transición a la democracia. Animus. Revista Interamericana de Comunicação Midiática, 16(32). Recuperado de https://doi.org/10.5902/2175497730436

Díaz, C. y Giménez, M. (2018a). La Nación frente al sindicalismo en los albores de la democracia argentina (1983-1985). Trabajo presentado en las X Jornadas de Sociología de la UNLP. Recuperado de http://jornadassociologia.fahce.unlp.edu.ar/Xjornadas/actas/DiazPONmesa5o.pdf/view?searchterm=None

Díaz, C. y Giménez, M. (2018b). Los editoriales de La Nación en pos de la institucionalidad liberal durante los dos primeros años de Alfonsín.

Actas de Periodismo y Comunicación, 4(3). Recuperado de https://perio.unlp.edu.ar/ojs/index.php/actas/article/view/5442/4693

Díaz, C., Giménez, M. y Passaro, M. (2008). 19 de mayo de 1977: «De eso no se habla», Anuario de Investigaciones 2006 (pp. 61-69). La Plata, Argentina: Universidad Nacional de La Plata.

Díaz, J. y López, J. (2018). Una mirada periodística acerca de la judicatura en los albores de la restauración del orden constitucional argentino: La Nación y Clarín, 1984. Actas de Periodismo y Comunicación, 4(2). Recuperado de https://perio.unlp.edu.ar/ojs/index.php/actas/article/view/5380/4636

Diccionarios Rioduero (1984). Mitología griega y romana. Madrid, España: RiodueroGuaflex editorial.

Ducrot, O. (1989). El decir y lo dicho. Ciudad Autónoma de Buenos Aires, Argentina: Hachette.

Giménez, M. (2015). El hito de la guerra de Malvinas y el futuro de la Argentina en los editoriales de La Nación. En César L. Díaz (Coord.) (2017), El periodismo gráfico durante la dictadura (pp. 243-266). La Plata, Argentina: EPC. Recuperado de http://sedici.unlp.edu.ar/handle/10915/65166

LV12 (1 de octubre de 2016). Manzur participó del cierre de la Asamblea General de Adepa. Recuperado de https://www.lv12.com.ar/manzur-participo-del-cierre-laasamblea-general-adepa-n13584

Maingueneau, D. (1989). Introducción a los métodos del análisis del discurso. Ciudad Autónoma de Buenos Aires, Argentina: Hachette. 
Rivadeneira Prada, R. (1986). Periodismo. La teoría general de los sistemas y la ciencia de la comunicación. Ciudad de México, México: Trillas.

Sidicaro, R. (1993). La política mirada desde arriba. Ciudad Autónoma de Buenos Aires, Argentina: Sudamericana.

Unión Cívica Radical (1983). Plataforma electoral para las elecciones presidenciales. Recuperado de https://www.educ.ar/recursos/129117/plataforma-electoral-ucr-1983 Verón, E. (1987). La palabra adversativa. En AA.VV., El discurso político. Lenguajes y acontecimientos (pp. 11-26). Ciudad Autónoma de Buenos Aires, Argentina: Hachette. Verón, E. (2005). Fragmentos de un tejido. Barcelona, España: Gedisa.

\section{Fuentes analizadas}

La Nación. (28 de diciembre de 1983). La ley de radiodifusión y el nuevo gobierno.

La Nación. (30 de diciembre de 1983). Agencia informativa de gobiernos americanos.

La Nación. (4 de enero de 1984). La UNESCO y la libertad de prensa.

La Nación. (16 de marzo de 1984). Televisión y objetividad.

La Nación. (10 de septiembre de 1984). El artículo 45 de la Ley de Radiodifusión.

La Nación. (30 de octubre de 1984). La Unesco y la libertad de prensa.

La Nación. (30 de diciembre de 1984). La situación de la Unesco.

La Nación. (7 de marzo de 1985). El "nuevo orden informativo" de la Unesco.

La Nación. (7 de mayo de 1985). Amenazas a la libertad de prensa.

La Nación. (15 de mayo de 1985). La Secretaría de Información Pública.

La Nación. (13 de junio de 1985). La libertad de expresión en radio y TV.

La Nación. (23 de junio de 1985). La próxima asamblea general de la Unesco.

La Nación. (21 de julio de 1985). Libertad de prensa y derecho de réplica.

La Nación. (27 de octubre de 1985). La SIP y la libertad de prensa.

La Nación. (1 de noviembre de 1985). El Estado y la radioteledifusión. 
La Nación. (12 de enero de 1986). La Ley de Radiodifusión y las provincias.

La Nación. (1 de febrero de 1986). Leyes provinciales de radiodifusión.

La Nación. (26 de febrero de 1986). Grave lesión a la libertad de prensa.

La Nación. (12 de marzo de 1986). «Sin prensa libre no existe libertad» (comillas en el original).

La Nación. (6 de abril de 1986). Derecho de réplica en San Juan.

La Nación. (1 de junio de 1986) Condena mundial al derecho de réplica.

La Nación. (29 de agosto de 1986). La misión de la prensa independiente.

La Nación. (19 de septiembre de 1986). Un llamado de atención que no aceptamos.

La Nación. (31 de octubre de 1986). Radio y TV oficiales a perpetuidad.

La Nación. (9 de enero de 1987). Promesas incumplidas sobre radiodifusión.

La Nación. (24 de febrero de 1987). La futura Ley de Radiodifusión.

La Nación. (11 de mayo de 1987). Sin libertad de opinión no hay democracia.

La Nación. (22 de mayo de 1987). La asamblea del IPI.

La Nación. (2 de junio de 1987). Nueva amenaza a la libertad de prensa.

La Nación. (3 de agosto de 1987). Conflictos por la Ley de Radiodifusión.

La Nación. (1o de agosto de 1987). La crítica a los funcionarios públicos.

La Nación. (3 de septiembre de 1987). Los medios de comunicación independientes.

La Nación. (11 de septiembre de 1987). El destino de la Unesco.

La Nación. (23 de octubre de 1987). La Unesco en una hora decisiva.

La Nación. (25 de noviembre de 1987). Anteproyecto sobre la ley de radiodifusión.

La Nación. (27 de noviembre de 1987). La libertad de prensa en América.

La Nación. (10 de diciembre de 1987). Derecho a réplica en Chubut.

La Nación. (13 de diciembre de 1987). Veto al derecho de réplica en Chubut. 
1 Este trabajo forma parte del proyecto de investigación «El primer gobierno posdictadura bajo la lupa editorial de La Nación y Clarín (1983-1989)», dirigido por el Dr. César Luis Díaz.

2 Para abrevar en la larga historia del matutino puede consultarse la obra de Ricardo Sidicaro (1993).

3 Esgrimimos esta noción apelando a la mitología griega, según la cual este hijo de Zeus era un mensajero divino. Apolo le dio una vara mágica, que con el gorro alado y los zapatos también alados fueron característicos de Hermes. Con la vara podía adormecer o despertar a los humanos. Posteriormente, la vara mágica se convirtió en bastón de heraldo, o sea en atributo del mensajero de los dioses. Además, los «Hermes» constituían mojones que servían de guía a los caminantes. Otro rasgo distintivo de este dios era su astucia y su ingenio para el engaño (Diccionarios Rioduero, 1984).

4 La Ley 22.285 fue sancionada en 1980 durante la gestión del dictador Jorge Rafael Videla.

5 El presidente, «por medio del decreto 1154 de abril de 1984, suspendió la aplicación del Plan Nacional de Radiodifusión (PLANARA), hasta que no se modificase la Ley de Radiodifusión» (Com, 2009, p. 199), pero esto no tendría ningún reconocimiento editorial en el matutino examinado.

6 Según María Cristina Basombrío (2017), eran diversos medios gráficos los que remarcaban estas disidencias en el seno del partido de gobierno.

7 Esta entidad, fundada en 1946, «ha sido desde su creación un foro para la defensa de las garantías que aseguran la diversidad de las fuentes de información, como la Sociedad Interamericana de Prensa (SIP) lo ha sido en el ámbito de la prensa escrita» (13/06/1985).

8 La Nación recuperaría la membresía en esta entidad durante 1984. Recuérdese que junto con sus «socios» (La Razón y Clarín) se habían retirado de ADEPA pues el resto de sus pares denunciaba la discriminación que estos tres diarios ejercían sobre ellos merced al control que tenían de la empresa Papel Prensa S.A. (Díaz, Giménez \& Passaro, 2008). En tanto, en la $54^{\circ}$ Asamblea General de la institución, realizada en octubre de 2016, José Escribano, de La Nación, evocaría: «Recuerdo que la última Asamblea (en Tucumán), en 1986, estábamos muy divididos como suele ocurrir en las instituciones, pero esta es la mejor que recuerde de los últimos quince años, por la coincidencia de los puntos que se trataron y la valoración del último ejercicio» (LV12, o1/10/2016).

9 Respecto de esta provincia, volvería criticar este derecho el 18 de marzo de 1987.

$10 \mathrm{Al}$ año siguiente, una nueva asamblea de esta organización reiteró su rechazo al «mal llamado "derecho de réplica" [que] lamentablemente está encontrando numerosos sostenedores en el campo gubernamental de nuestro país» (22/05/1987). 
11 Creada en julio de 1985, estaba integrada por la Asociación Argentina de Editores de Revistas (AAER), la Asociación de Diarios del Interior de la República Argentina (ADIRA), la Asociación de Editores de Diarios de la ciudad de Buenos Aires (AEDBA), la Asociación Radiodifusoras Privadas Argentinas (ARPA) y la Asociación de Teleradiodifusoras Argentinas (ATA).

12 En la nota publicada en referencia a las segundas jornadas de la cemci señaló: «Autorizadas voces se alzaron durante las jornadas para deplorar la pretendida institucionalización del mal llamado derecho de réplica [advirtiendo] que "ningún gobierno es el árbitro de la verdad" y que el único que debe cumplir esa función es el público» (03/09/1987).

13 Reiteraría el cuestionamiento de la SIP en el editorial del 25 de septiembre de 1986.

14 Similares consideraciones expresaría en las notas del 25 y el 27 de noviembre de 1987.

15 Volvería a criticar a esta agencia el 22 de octubre de 1985.

16 Se refiere al anuncio de los EE.UU. de retirarse de la UNESCO y, con ello, dejar al organismo sin el $25 \%$ de su financiamiento total. En otra nota, confirmaría que la salida de los EE.UU. se había producido, al tiempo que señalaría: «Gran Bretaña, por su parte, ha hecho saber que tomará idéntica medida a fines de 1985» (30/12/1984).

17 En otra nota crítica sobre el NOMIC, y en virtud del posible cambio de autoridades de la UNESCO, anunciaba que el gobierno de Francois Mítterrand había decidido «presionar firmemente para obtener reformas sustanciales o, en caso contrario, era preferible abandonar a su suerte al actual director general» (23/06/1985).

18 En las segundas jornadas de la CEMCI reiteró que «autorizadas voces se alzaron durante las jornadas para deplorar [...] la adhesión no oculta a un pretendido nuevo orden informativo prohijado por la Unesco, cuya filiación totalitaria se percibe a simple vista» (03/09/1987). 